\title{
Evaluation of comprehensive geriatric assessment in older patients undergoing pacemaker implantation
}

\author{
Andreas W. Schoenenberger ${ }^{1}$, lan Russi ${ }^{2}$, Benjamin Berte ${ }^{2}$, Vanessa Weberndörfer ${ }^{2}$, \\ Renate Schoenenberger-Berzins ${ }^{3}$, Piotr Chodup ${ }^{2}$, Remo Beeler ${ }^{2}$, Florim Cuculi ${ }^{2}$, Stefan Toggweiler ${ }^{2}$ and \\ Richard Kobza ${ }^{2 *}$ (D)
}

\begin{abstract}
Background: This study evaluated the use of comprehensive geriatric assessment (CGA) in older patients undergoing pacemaker implantation.

Methods: In this prospective cohort, CGA was performed in 197 patients $\geq 75$ years at pacemaker implantation and yearly thereafter. CGA embraced the following domains: cognition, mobility, nutrition, activities of daily living (ADLs), and falls (with or without loss of consciousness). Based on comorbidities, the Charlson comorbidity index (CCI) was calculated. For predictive analysis, logistic regression was used.
\end{abstract}

Results: During a mean follow-up duration of 2.4 years, the incidence rates of syncope decreased from 0.46 to 0.04 events per year $(p<0.001)$, and that of falls without loss of consciousness from 0.27 to $0.15(p<0.001)$ before vs. after implantation. Sixty-three patients (32.0\%) died. Impaired mobility (OR 2.60, 95\%Cl 1.22-5.54, $p=0.013$ ), malnutrition (OR 3.26, 95\%Cl 1.52-7.01, $p=0.002$ ), and a higher CCl (OR per point increase 1.25, 95\%Cl 1.04-1.50, $p=0.019$ ) at baseline were significant predictors of mortality. Among 169 patients who survived for more than 1 year and thus underwent follow-up CGA, CGA domains did not deteriorate during follow-up, except for ADLs. This decline in ADLs during follow-up was the strongest predictor of later nursing home admission (OR 9.29, 95\% Cl $1.82-47.49, p=0.007$ ). Higher baseline age (OR per year increase 1.10,95\% Cl 1.02-1.20, $p=0.018$ ) and a higher baseline $\mathrm{CCl}(\mathrm{OR}$ per point increase $1.32,95 \% \mathrm{Cl} 1.05-1.65, p=0.017)$ were associated with a decline in ADLs during follow-up.

Conclusions: CGA is useful to detect functional deficits, which are associated with mortality or nursing home admission after pacemaker implantation. The present study seems to support the use of CGA in older patients undergoing pacemaker implantation as functional deficits and falls are amenable to geriatric interventions.

Keywords: Pacemaker, Geriatric assessment, Charlson comorbidity index

\section{Background}

In industrialized countries, the use of pacemakers in older patients will increase in the future due to

* Correspondence: richard.kobza@luks.ch

${ }^{2}$ Heart Center Lucerne, Luzerner Kantonsspital, 6000 Lucerne 16, Switzerland Full list of author information is available at the end of the article epidemiologic and demographic changes [1]. Previous studies have shown that pacemaker implantations have favorable effects on mortality, syncope and quality of life in older patients [2-5]. However, these outcomes reflect only part of important outcomes in older patients, since functional outcomes after cardiologic interventions are similarly important [6,7]. Moreover, it has been shown

(c) The Author(s). 2020 Open Access This article is licensed under a Creative Commons Attribution 4.0 International License, which permits use, sharing, adaptation, distribution and reproduction in any medium or format, as long as you give appropriate credit to the original author(s) and the source, provide a link to the Creative Commons licence, and indicate if changes were made. The images or other third party material in this article are included in the article's Creative Commons licence, unless indicated otherwise in a credit line to the material. If material is not included in the article's Creative Commons licence and your intended use is not permitted by statutory regulation or exceeds the permitted use, you will need to obtain permission directly from the copyright holder. To view a copy of this licence, visit http://creativecommons.org/licenses/by/4.0/. The Creative Commons Public Domain Dedication waiver (http://creativecommons.org/publicdomain/zero/1.0/) applies to the data made available in this article, unless otherwise stated in a credit line to the data. 
that functional limitations prior to interventions are associated with mortality and worse functional outcomes [6, 8-13]. Pre-procedural functional limitations as well as functional outcomes after interventions are usually ascertained using comprehensive geriatric assessment (CGA) [14]. CGA covers important functional domains, such as cognition, mobility, nutrition, activities of daily living, or falls (with or without loss of consciousness) [14].

Though a recent position paper on pacemaker management suggests performing geriatric assessment in older patients, it is only rarely used in clinical routine [1]. This underuse may be partially explained by a lack of good evidence in current literature. To the best of the authors' knowledge, no previous study evaluated CGA in older patients undergoing pacemaker implantation. Despite an extensive literature search, the authors found only one small study that evaluated cognitive function in 19 patients undergoing pacemaker implantation [15]. The present study therefore aimed to fill this scientific gap and to evaluate CGA in a prospective cohort of older patients undergoing pacemaker implantation.

\section{Methods}

\section{Study population}

Consecutive patients $\geq 75$ years of age undergoing pacemaker implantation and being followed at the Heart Center Lucerne (Lucerne, Switzerland) between March 1st, 2012, and March 31st, 2017, were eligible for this prospective cohort study. The following patients were excluded from the study: first, patients who refused study participation and did not provide a signed informed consent; second, patients in whom baseline assessment was unfeasible due to logistic reasons. Patients with intracardiac cardioverter devices (ICDs) were also excluded. The final study population consisted of all patients in whom pacemaker implantation and baseline examination were performed during the study period. This study complies with the Declaration of Helsinki and was approved by the local ethics committee.

\section{Baseline evaluation}

All participating patients received extensive cardiologic baseline examination according to current guidelines [16]. Patient history was recorded including symptoms, cardiovascular risk factors, medication, prior cardiovascular events, as well as comorbidities. Physical examination included standard parameters such as body weight, height and blood pressure. Based on the number of comorbidities, the Charlson comorbidity index (CCI) was calculated [17].

In addition, all participating patients underwent CGA involving instruments for functional status. CGA consisted of the following validated instruments: Mini
Mental State Exam (MMSE) for cognitive function [18], Timed Get Up and Go Test (TUG) for gait function [19], Mini Nutritional Assessment (MNA) for nutritional status [20], Basic Activities of Daily Living (BADL) [21], and Instrumental Activities of Daily Living (IADL) [22]. The number of falls without loss of consciousness and/ or syncopes in the preceding 12 months were assessed using standardized questions. The instruments were dichotomized at standard cut points. The latter were defined from the outset: MMSE at $<27$ points (cognitive impairment) vs. $\geq 27$ points (normal cognitive function), TUG at $\geq 20 \mathrm{~s}$ (mobility impairment) vs. $<20 \mathrm{~s}$ (normal gait function), MNA at $<12$ points (at risk of malnutrition) vs. $\geq 12$ points (not at risk of malnutrition) [18-20]. If there was one or more activity with a limitation, BADL and IADL were considered abnormal [21, 22]. In addition to the functional assessment, the emotional status was assessed using the 5-item geriatric depression scale (GDS), which was dichotomized at $\geq 2$ points (at risk of depression) vs. $<2$ points (not at risk of depression) [23].

\section{Pacemaker implantation}

Pacemaker implantations were performed by five experienced operators according to best clinical practice respecting the current guideline recommendation [16]. Dual chamber pacemakers were implanted in 159 patients, single chamber devices in 33 patients and 5 patients received a biventricular system.

\section{Follow-up}

A routine follow-up was performed yearly at the Heart Center Lucerne in all participants. The study participants were invited by mail and/or phone. In case the participants did not respond to the invitation, the treating general practitioner and/or registered relatives were contacted. During the on-site visit, the pacemaker was interrogated and patients underwent a cardiological examination as well as CGA. CGA consisted of the same instruments that were used at baseline. CGA also assessed the number of falls without loss of consciousness and/or syncopes since the baseline examination or the last follow-up, respectively. In case of death phone interviews were done with the treating general practitioner and/or relatives to ascertain the circumstances. Death and the time of death were crosschecked using the official register of the local authorities.

\section{Outcomes}

Mortality was the main outcome and defined as overall mortality from cardiac or non-cardiac causes. Changes in the incidence of syncope and falls between the preand post-implantation period was another outcome. Syncope was defined as fall with a short period of 
unconsciousness, whereas a drop without loss of consciousness was considered a fall. As a further outcome, we determined the change of functional status between baseline and follow-up comparing the single CGA domains between baseline and follow-up. Based on BADL and IADL, we defined the outcome decline in activities of daily living (decline in ADLs), which corresponded to a deterioration of $\geq 1$ activity in the ability to perform BADL and/or IADL between baseline and follow-up. Regarding the outcome nursing home admission, only new admissions after pacemaker implantation were considered.

\section{Statistical analysis}

First, we descriptively analyzed mortality, syncope and falls without loss of consciousness during follow-up. Second, to compare rates of syncope and falls during follow-up with the pre-implantation period, incidence rates were calculated and compared using the incidence rate ratio (IRR) with its $95 \%$ confidence interval (CI). Third, we descriptively analyzed the change of functional status between baseline evaluation and last available follow-up examination among patients who survived for more than 1 year after pacemaker implantation and thus had at least one follow-up CGA. Fourth, in order to compare the functional status during follow-up with baseline, we used logistic regression reporting odds ratios (ORs) with 95\% CIs and $p$ values. Models were done unadjusted as well as adjusted for age, sex and the CCI. Fifth, we separately analyzed the functional course among surviving patients, who showed a baseline impairment in the respective domain. The rational for this analysis was the high clinical relevance of this subgroup; furthermore, due to the ceiling effect of the assessment instruments, improvements could only be shown for this subgroup. Sixth, we used multivariable logistic regression to identify associations between potentially predictive variables and the outcomes. The potentially predictive variables were selected a priori based on clinical considerations (i.e., age, sex, CCI, and the CGA domains). In the logistic models, the CCI was used as categorized variable with a range from 1 to 9 , and the CGA domains were dichotomized at the standard cut points. The area under the receiver operating characteristic curve (AUROC) was used to quantify predictive ability. Finally, we performed sensitivity analyses. For mortality prediction, we performed a sensitivity analysis using a modified CCI without cardiovascular comorbidities, but adding cardiovascular comorbidities (i.e., NYHA class, presence of coronary artery disease, previous myocardial infarction, and heart failure) as single independent variables to the logistic model. For the prediction of nursing home admission, we performed a further sensitivity analysis retaining the deceased patients in the regression model. Data were analyzed using Stata 12.1 (StataCorp LP, College Station, TX, USA).

\section{Results \\ Study population}

Between March 1st 2012 and March 31st 2017, 270 patients aged 75 years or older underwent pacemaker implantation (Fig. 1). Fifty-three patients were initially excluded: 42 patients refused participation, 11 did not have a complete baseline assessment due to logistic problems. Of 217 eligible patients, 11 (5.1\%) refused follow-up examination and 9 (4.1\%) were lost to followup. The study population finally consisted of 197 patients.

Baseline characteristics are shown in Table 1. Mean age was $82.9 \pm 4.9$ years (range $75-95$ years). Sinus node disease, higher degree atrioventricular block and atrial fibrillation were frequent ECG findings. Accordingly, the most frequent indication for pacemaker implantation was bradycardia (137 patients, 69.5\%). Syncope as well as falls without loss of consciousness were frequent events in the 12 months preceding the pacemaker implantation (Table 1). Thirty-seven patients (18.8\%) have suffered from severe injuries associated with the syncopal event or fall (e.g., bone fracture in 16 patients, bleeding needing intervention in 10 patients, traumatic brain injury in 8 patients, other serious injury in 3 patients). Many of the patients had functional limitations based on CGA (Table 1).

\section{Mortality, syncope and falls in all study participants}

During a mean follow-up of $2.4 \pm 1.4$ years and total observation time of 472 person-years, 63 patients $(32.0 \%)$ died. Most of these deaths $(88.9 \%)$ were considered to be of a non-cardiac origin (e.g., general weakness due to age, infectious disease, and/or carcinoma).

During follow-up, 19 syncopes and 71 falls without loss of consciousness occurred. Compared to the preimplantation period the incidence rate of syncope dramatically decreased from 0.46 to 0.04 events per year (IRR 0.09, 95\% CI 0.05-0.15, $p<0.001$ ), as did falls without loss of consciousness with a decreasing incidence rate from 0.27 to 0.15 events per year (IRR 0.56, 95\% CI $0.39-0.81, p<0.001)$.

\section{Functional course}

Table 2 shows the changes in functional and emotional status among the 169 patients with available follow-up CGA. Overall, functional and emotional status were well preserved until the last follow-up, with the exception of activities of daily living. BADL and IADL showed a significant deterioration over the study period.

An additional analysis of the subgroup of surviving patients with baseline impairment showed that relevant 


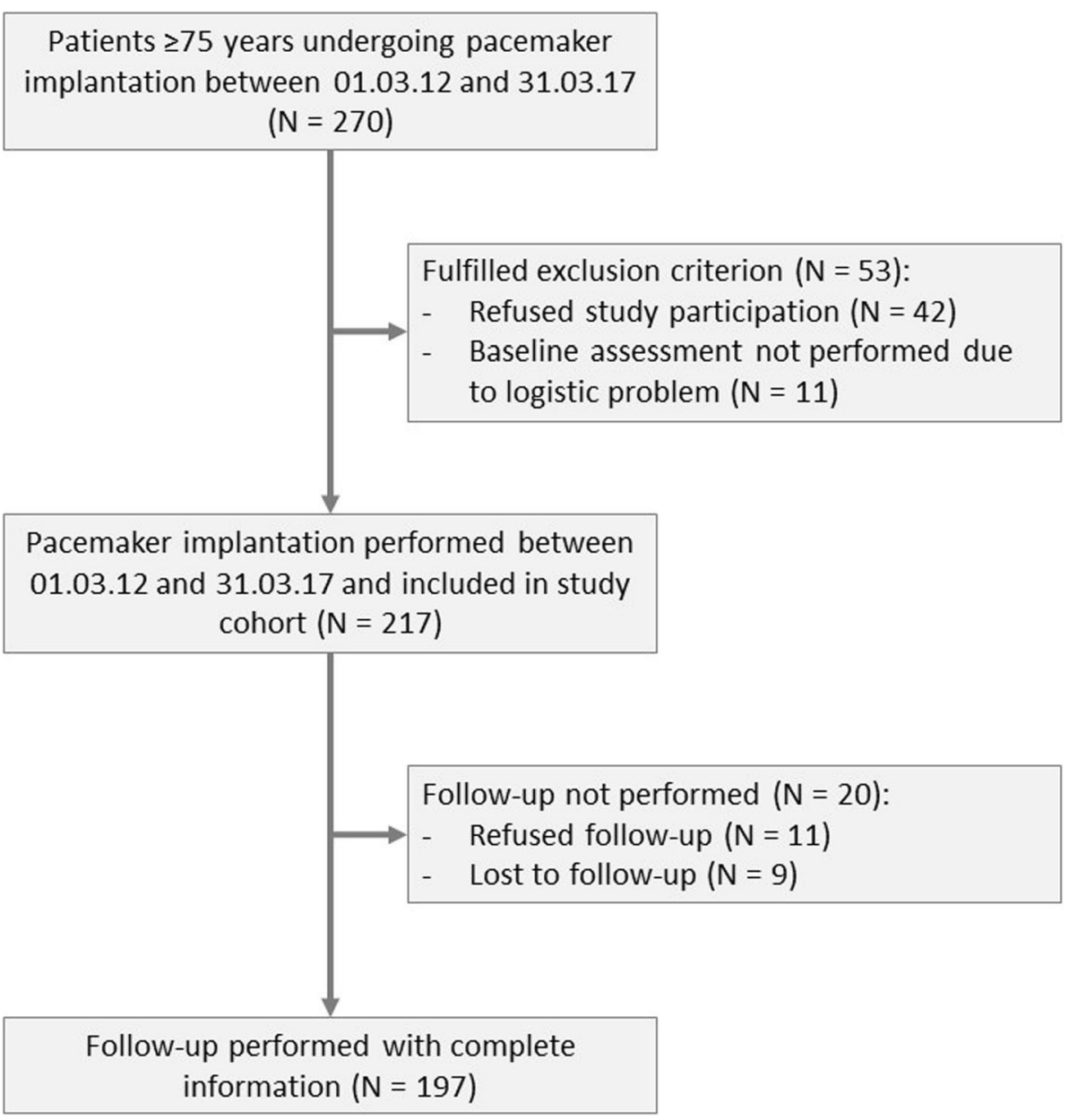

Fig. 1 Flow chart

proportions of these patients improved in their functional and emotional course. Among the 46 surviving patients with cognitive impairment at baseline, $27 \mathrm{pa}-$ tients (58.7\%) showed a cognitive improvement, 7 patients (15.2\%) remained unchanged, and only 12 patients (26.1\%) showed a further deterioration. Among the 37 surviving patients with mobility impairment at baseline, mobility improved in 21 patients $(56.8 \%)$, remained unchanged in 13 patients (35.1\%), and deteriorated in only 3 patients $(8.1 \%)$. Nutritional status improved in 36 (75.0\%) of the 48 surviving patients with risk of malnutrition at baseline, remained unchanged in 9 patients $(18.8 \%)$, and deteriorated in only 3 patients $(6.2 \%)$. Regarding BADL and IADL, improvements were found in 12 of 21 patients $(57.1 \%)$ with BADL limitations and 22 of 70 patients $(31.4 \%)$ with IADL limitations at baseline; a deterioration was found in 6 patients $(28.6 \%)$ for BADL and 26 patients (37.1\%) for IADL, respectively. Regarding emotional status, an improvement was found in 13 of 16 patients (81.3\%), while 3 patients $(18.7 \%)$ remained stable and no patient deteriorated.

\section{Predictive analyses}

In the predictive analysis, impaired mobility (OR 2.60 [95\% CI 1.22-5.54], $p=0.013$; AUROC 0.63 [95\% CI 0.56-0.70]), malnutrition (OR 3.26 [95\% CI 1.52-7.01], $p=0.002$; AUROC 0.65 [95\% CI 0.58-0.73]), a higher CCI (OR per point increase 1.25 [95\% CI 1.04-1.50], $p=0.019$; AUROC 0.68 [95\% CI $0.60-0.75]$ ), and age (OR per year increase 1.08 [95\% CI 1.00-1.16], $p=$ 0.049; AUROC 0.62 [95\% CI 0.53-0.70]) at baseline were significant predictors of mortality after the pacemaker implantation (Fig. 2). Of the 134 surviving patients, 13 patients $(9.7 \%)$ were newly admitted to a nursing home. The decline in ADLs from baseline to follow-up was found to be the strongest predictor of later nursing home admission (OR 9.29 [95\% CI 1.82-47.49], $p=$ 0.007; AUROC 0.72 [95\% CI 0.61-0.84]), whereas the baseline variables in the model (i.e., age, sex, CCI, and CGA domains) were not predictive of the outcome. In a logistic regression evaluating baseline factors associated with the decline in ADLs, significant associations were found for higher baseline age (OR per year increase 1.10 
Table 1 Baseline characteristics

\begin{tabular}{|c|c|}
\hline Characteristic & All study participants $(\boldsymbol{N}=197)$ \\
\hline Age, mean $\pm S D$, years & $82.9 \pm 4.9$ \\
\hline Female sex, n (\%) & $86(43.7 \%)$ \\
\hline Body Mass Index, mean $\pm \mathrm{SD}, \mathrm{kg} / \mathrm{m} 2$ & $25.7 \pm 4.2$ \\
\hline \multicolumn{2}{|l|}{ Cardiovascular risk factors } \\
\hline Hypertension, $\mathrm{n}(\%)$ & $155(78.7 \%)$ \\
\hline Hypercholesterolemia, n (\%) & $60(30.5 \%)$ \\
\hline Current smoker, n (\%) & $17(8.6 \%)$ \\
\hline Diabetes, n (\%) & $30(15.2 \%)$ \\
\hline Positive family history, $\mathrm{n}(\%)$ & $24(12.2 \%)$ \\
\hline \multicolumn{2}{|l|}{ Medical history } \\
\hline Coronary artery disease, n (\%) & $92(46.7 \%)$ \\
\hline Previous myocardial infarction, $\mathrm{n}(\%)$ & $16(8.1 \%)$ \\
\hline Valvular heart disease, $\mathrm{n}(\%)$ & $92(46.7 \%)$ \\
\hline Hypertensive heart disease, $\mathrm{n}(\%)$ & $40(26.9 \%)$ \\
\hline Hypertrophic cardiomyopathy, n (\%) & $24(12.2 \%)$ \\
\hline Previous stroke, n (\%) & $25(12.7 \%)$ \\
\hline Previous syncope within last 12 months, $n(\%)$ & $90(45.7 \%)$ \\
\hline Fall without loss of consciousness within last 12 months, $n$ (\%) & $53(26.9 \%)$ \\
\hline \multicolumn{2}{|l|}{ Electrocardiogram } \\
\hline Sinus node disease, $n(\%)$ & 49 (24.9\%) \\
\hline \multicolumn{2}{|l|}{ Atrioventricular block } \\
\hline - Second-degree, n (\%) & $39(19.8 \%)$ \\
\hline - Third-degree, n (\%) & $51(25.9 \%)$ \\
\hline Atrial fibrillation, n (\%) & $59(29.9 \%)$ \\
\hline \multicolumn{2}{|l|}{ Comprehensive geriatric assessment } \\
\hline Cognitive impairment (MMSE < 27 points), n (\%) & $84(42.6 \%)$ \\
\hline Mobility impairment (TUG $\geq 20$ s), n (\%) & $71(36.0 \%)$ \\
\hline At risk of malnutrition (MNA < 12 points), $\mathrm{n}(\%)$ & $90(45.7 \%)$ \\
\hline BADL with $\geq 1$ activity with limitation, $n(\%)$ & $39(19.8 \%)$ \\
\hline IADL with $\geq 1$ activity with limitation, $n(\%)$ & $110(55.8 \%)$ \\
\hline \multicolumn{2}{|l|}{ Emotional assessment } \\
\hline At risk of depression (GDS $\geq 2$ points), $n(\%)$ & $34(17.3 \%)$ \\
\hline \multicolumn{2}{|l|}{ Comorbidity burden } \\
\hline Charlson comorbidity index $\geq 3, n(\%)$ & $98(49.8 \%)$ \\
\hline
\end{tabular}

Abbreviations: BADL basic activities of daily living, GDS geriatric depression scale, IADL instrumental activities of daily living, MMSE mini mental state exam, MNA mini nutritional assessment, TUG timed get up and go test

[95\% CI 1.02-1.20], $p=0.018 ;$ AUROC 0.58 [95\% CI $0.49-0.68]$ ) and a higher CCI (OR per point increase 1.32 [95\% CI 1.05-1.65], $p=0.017$; AUROC 0.59 [95\% CI 0.49-0.68]).

\section{Sensitivity analyses}

Using cardiovascular comorbidities as single independent predictors in the model for mortality prediction, impaired mobility, malnutrition, and the modified CCI were unvaried the significant predictors of mortality after pacemaker implantation, whereas the cardiovascular comorbidities did not significantly predict mortality.
Including the deceased patients in the analysis for the prediction of nursing home admission, the decline in ADLs from baseline to follow-up remained the strongest predictor of later nursing home admission (OR 9.92 [95\% CI 2.12-46.48], $p=0.004)$.

\section{Discussion}

The results from this prospective cohort show that, apart from higher age and higher comorbidity burden, impaired mobility and malnutrition were significantly associated with mortality after pacemaker implantation. Mortality in this cohort was high with nearly one of 
Table 2 Functional and emotional course $(N=169)$

\begin{tabular}{|c|c|c|c|c|c|c|}
\hline \multirow[t]{3}{*}{ Domain } & \multirow{3}{*}{$\begin{array}{l}\text { Baseline } \\
N(\%)\end{array}$} & \multirow{3}{*}{$\begin{array}{l}\text { Follow-up } \\
N(\%)\end{array}$} & \multicolumn{4}{|c|}{ Regression analysis } \\
\hline & & & \multicolumn{2}{|l|}{ Unadjusted } & \multicolumn{2}{|l|}{ Adjusted $^{\mathrm{a}}$} \\
\hline & & & $O R(95 \% C l)^{b}$ & $P$ value ${ }^{b}$ & OR $(95 \% C l)^{b}$ & $P$ value ${ }^{b}$ \\
\hline \multicolumn{7}{|l|}{ Cognition } \\
\hline Cognitive impairment (MMSE < 27 points) & $64(37.9 \%)$ & $69(40.8 \%)$ & $1.13(0.73-1.75)$ & 0.578 & $1.15(0.73-1.81)$ & 0.560 \\
\hline \multicolumn{7}{|l|}{ Mobility } \\
\hline Mobility impairment (TUG $\geq 20$ s) & $55(32.5 \%)$ & 49 (29.0\%) & $0.85(0.54-1.36)$ & 0.502 & $0.85(0.53-1.37)$ & 0.504 \\
\hline \multicolumn{7}{|l|}{ Activities of daily living } \\
\hline BADL with $\geq 1$ activity with limitation & $29(17.2 \%)$ & $48(28.4 \%)$ & $1.92(1.14-3.23)$ & 0.015 & $2.18(1.23-3.88)$ & 0.008 \\
\hline IADL with $\geq 1$ activity with limitation & $90(53.3 \%)$ & $121(71.6 \%)$ & $2.21(1.41-3.47)$ & 0.001 & $2.59(1.57-4.26)$ & $<0.001$ \\
\hline \multicolumn{7}{|l|}{ Nutrition } \\
\hline At risk of malnutrition (MNA < 12 points) & $71(42.0 \%)$ & $60(35.5 \%)$ & $0.76(0.49-1.18)$ & 0.220 & $0.74(0.47-1.17)$ & 0.198 \\
\hline \multicolumn{7}{|l|}{ Emotion } \\
\hline At risk of depression (GDS $\geq 2$ points) & $22(13.0 \%)$ & $24(14.2 \%)$ & $1.11(0.59-2.06)$ & 0.751 & $1.11(0.59-2.08)$ & 0.749 \\
\hline
\end{tabular}

three patients dying during the relatively short mean follow-up duration of little more than 2 years. Pacemaker implantation not only improved the occurrence of syncope, but also led to a highly relevant decrease in falls without loss of consciousness. Our study further shows that functional status remains stable in surviving patients after pacemaker implantation except for activities of daily living, which deteriorated during follow-up. The decline in ADLs was the most important factor being significantly associated with nursing home admission during follow-up.

Mortality after pacemaker implantation was high in our cohort, but comparable to previous studies involving similar patients $[2-5,24,25]$. Mortality, syncope and quality of life of elderly patients undergoing pacemaker implantation have been well investigated in these previous studies, but to our knowledge this is the first study evaluating CGA in older patients undergoing pacemaker implantation. This study documents the importance of additionally assessing falls without loss of consciousness and the functional course after pacemaker implantation using standardized CGA instruments. This study therefore adds to a growing evidence from other surgical or interventional procedures that CGA is important for the assessment of functional outcomes as well as for outcome prediction [6-13, 26].

This study has clinical implications. It demonstrated that older malnourished patients with impaired mobility have a greater risk of dying after a pacemaker implantation. CGA is suited to detect these functional deficits. Recent systematic analyses of randomized controlled studies have shown that CGA and subsequent interventions based on CGA improve prognosis and decrease nursing home admissions among older patients [27, 28]. This study shows that a decline in ADLs during followup increases the risk of nursing home admission. CGA during follow-up detects this deterioration, which may prompt interventions aiming at reversing the decline in ADLs. Therefore, the present study seems to support the use of CGA in older patients undergoing pacemaker implantation.

This study also shows that a relevant proportion of patients with functional limitations at baseline recover from these limitations after pacemaker implantation. We presume that in some patients the functional limitations are the consequence of hemodynamic compromises due to the cardio-electric dysfunction leading to pacemaker implantation. This study therefore underlines the importance of performing pacemaker implantation even in the oldest old.

This study has limitations. First, the findings of this study are based on data from a single center. Therefore, generalizability of the findings of the present study is limited. Second, though the sample size was adequate for most analyses, the number of study participants and endpoints was probably too low for certain analyses. It is conceivable that some of the non-significant results might be the consequence of a type II error. Third, 9 of the 217 patients $(4.1 \%)$ included in the study cohort were lost to follow-up without information on mortality, which may have biased our follow-up results to a certain extent. Fourth, as functional course could only be analyzed for patients, who did not die during the first year of follow-up and thus underwent follow-up CGA, the results of functional course might be biased to some extent. However, we performed a sensitivity analysis for 
a

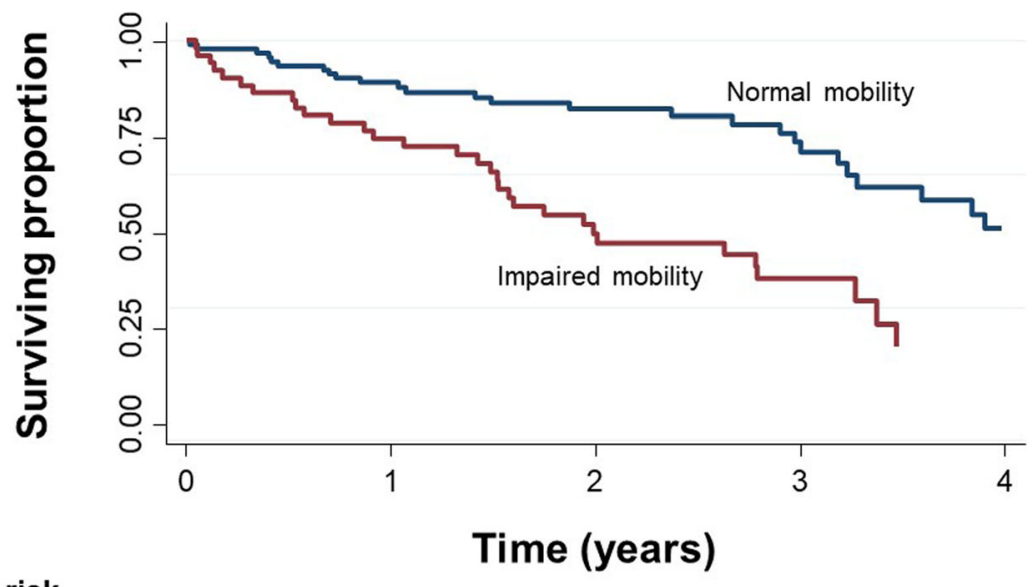

Number at risk

$\begin{array}{llllll}\text { Normal mobility } & 126 & 102 & 80 & 45 & 23 \\ \text { Impaired mobility } & 71 & 55 & 36 & 18 & 10\end{array}$

b

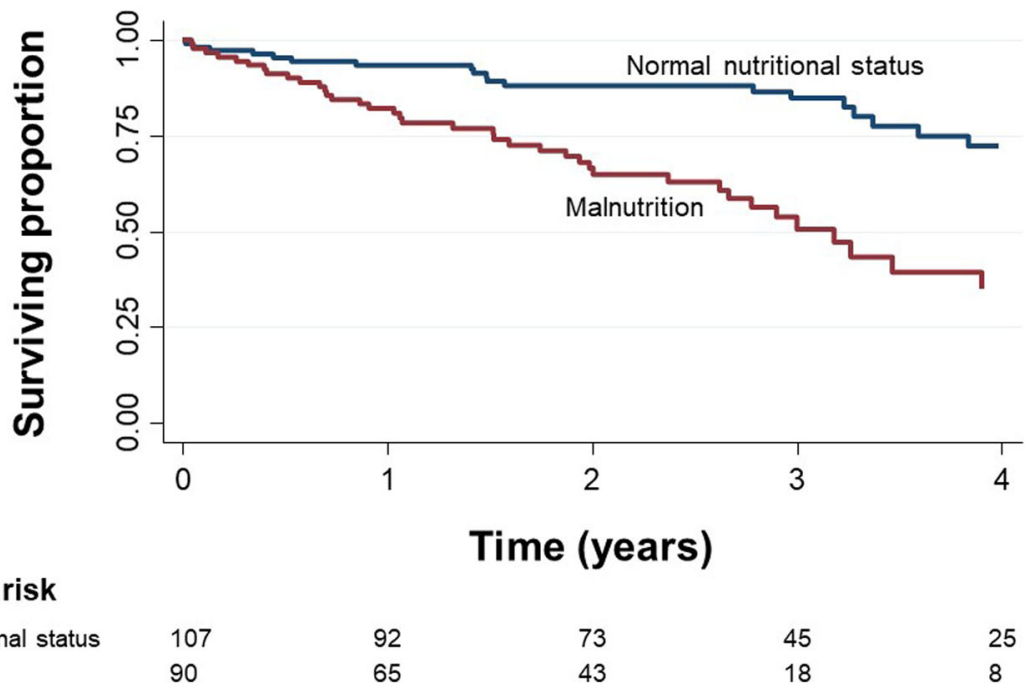

$\begin{array}{llllll}\text { Number at risk } & & & 45 & 25 \\ \text { Normal nutritional status } & 107 & 92 & 73 & 18 & 8 \\ \text { Malnutrition } & 90 & 65 & 43 & \end{array}$

Fig. 2 a Kaplan-Meier survival estimates stratified by mobility at baseline. b Kaplan-Meier survival estimates stratified by nutritional status at baseline

the prediction of nursing home admission including the deceased patients, which showed no relevant change of the predicting factors. Finally, this study only documents associations of CGA with important outcomes, but, due to the nature of a cohort study, fails to show whether or not CGA ultimately improved patient outcomes. Therefore, this study also has implications for research. Randomized controlled trials are urgently needed to determine the effect of CGA on outcomes in specific clinical conditions, such as cardiologic, surgical or oncologic procedures [26].

\section{Conclusion}

This study shows that CGA is a useful tool to detect functional deficits, which are associated with mortality or nursing home admission after pacemaker implantation. The present study seems to support the use of CGA in older patients undergoing pacemaker implantation as functional deficits and falls are amenable to geriatric interventions.

\section{Abbreviations}

ADLs: Activities of daily living; BADL: Basic activities of daily living;

CCl: Charlson comorbidity index; CGA: Comprehensive geriatric assessment; Cl: Confidence interval; GDS: Geriatric depression scale; IADL: Instrumental activities of daily living; IRR: Incidence rate ratio; MMSE: Mini mental state exam; MNA: Mini nutritional assessment; OR: Odds ratio; TUG: Timed get up and go test

Acknowledgements

We would like to thank the study nurses for helping with patient follow-up. 


\section{Authors' contributions}

AW has made substantial contributions to the design of the work, made substantial contributions to the interpretation of the data and has drafted the work. IR has made substantial contributions to the acquisition of the data. BB has made substantial contributions to the acquisition of the data and made substantial contributions to the interpretation of data. WW has made substantial contributions to the acquisition of the data. RS has made substantial contributions to the design of the work and has revised the work substantively. PC has made substantial contributions to the interpretation of data. RB has made substantial contributions to the acquisition of the data. FC made substantial contributions to the interpretation of data and has substantively revised the work. ST made substantial contributions to the interpretation of data and has substantively revised the work. RK has made substantial contributions to the design of the work, made substantial contributions to the acquisition and interpretation of the data and has substantively revised the work. All authors have read and approved the final manuscript.

\section{Funding}

Not applicable.

\section{Availability of data and materials}

The datasets used and/or analysed during the current study are available from the corresponding author on reasonable request.

\section{Ethics approval and consent to participate}

This study complies with the Declaration of Helsinki and was approved by the local ethics committee (Ethikkommission Nordwest- und Zentralschweiz, Switzerland; committee's reference number KEK Luzern 12045). Written informed consent to participate in the study was obtained from all participants.

\section{Consent for publication}

Written consent to publish their study results was obtained from all participants.

\section{Competing interests}

RK has received institutional grant support from Abbott, Biotronik, Biosense Webster, Boston, Medtronic and SIS Medical.

\section{Author details}

'Department of Geriatrics, Inselspital, Bern University Hospital, and University of Bern, Bern, Switzerland. 'Heart Center Lucerne, Luzerner Kantonsspital, 6000 Lucerne 16, Switzerland. ${ }^{3}$ Department of Cardiology, University Hospital Zurich, Zurich, Switzerland.

\section{Received: 4 May 2019 Accepted: 31 July 2020}

\section{Published online: 12 August 2020}

\section{References}

1. Fauchier L, Alonso C, Anselme F, Blangy H, Bordachar P, Boveda S, Clementy N, Defaye P, Deharo JC, Friocourt P, Gras D, Halimi F, Klug D, Mansourati J, Obadia B, Pasquié JL, Pavin D, Sadoul N, Taieb J, Piot O, Hanon O. Position paper for management of elderly patients with pacemakers and implantable cardiac defibrillators: Groupe de Rythmologie et Stimulation Cardiaque de la Société Française de Cardiologie and Société Française de Gériatrie et Gérontologie. Arch Cardiovasc Dis. 2016;109:563-85.

2. Lamas GA, Orav EJ, Stambler BS, Ellenbogen KA, Sgarbossa EB, Huang SK, Marinchak RA, Estes NA 3rd, Mitchell GF, Lieberman EH, Mangione CM, Goldman L. Quality of life and clinical outcomes in elderly patients treated with ventricular pacing as compared with dual-chamber pacing. Pacemaker selection in the elderly investigators. N Engl J Med. 1998;338:1097-104.

3. Mandawat A, Curtis JP, Mandawat A, Njike VY, Lampert R. Safety of pacemaker implantation in nonagenarians: an analysis of the healthcare cost and utilization project-nationwide inpatient sample. Circulation. 2013; 127:1453-65.

4. Udo EO, van Hemel NM, Zuithoff NP, Kelder JC, Crommentuijn HA, Koopman-Verhagen AM, Voskuil T, Doevendans PA, Moons KG. Long-term outcome of cardiac pacing in octogenarians and nonagenarians. Europace. 2012;14(4):502-8.
5. Dang D, Galand V, Loirat A, Auffret V, Behar N, Mabo P, Daubert JC, Leclerca C, Martins RP. Procedural safety and long-term follow-up after pacemaker implantation in nonagenarians. Clin Cardiol. 2018;41:1315-21.

6. Schoenenberger AW, Stortecky S, Neumann S, Moser A, Jüni P, Carrel T, Huber C, Gandon M, Bischoff S, Schoenenberger CM, Stuck AE, Windecker S, Wenaweser P. Predictors of functional decline in elderly patients undergoing transcatheter aortic valve implantation (TAVI). Eur Heart J. 2013; 34:684-92.

7. Schoenenberger AW, Zuber C, Moser A, Zwahlen M, Wenaweser P, Windecker S, Carrel T, Stuck AE, Stortecky S. Evolution of cognitive function after transcatheter aortic valve implantation. Circ Cardiovasc Interv. 2016; 9(10):e003590 Epub 2016 Sep 21.

8. Stortecky S, Schoenenberger AW, Moser A, Kalesan B, Jüni P, Carrel T, Bischoff S, Schoenenberger CM, Stuck AE, Windecker S, Wenaweser P. Evaluation of multidimensional geriatric assessment as a predictor of mortality and cardiovascular events after transcatheter aortic valve implantation. JACC Cardiovasc Interv. 2012:5:489-96.

9. Makary MA, Segev DL, Pronovost PJ, Syin D, Bandeen-Roche K, Patel P, Takenaga R, Devgan L, Holzmueller CG, Tian J, Fried LP. Frailty as a predictor of surgical outcomes in older patients. J Am Coll Surg. 2010;210:901-8.

10. Lee DH, Buth KJ, Martin BJ, Yip AM, Hirsch GM. Frail patients are at increased risk for mortality and prolonged institutional care after cardiac surgery. Circulation. 2010;121:973-8.

11. Afilalo J, Eisenberg MJ, Morin JF, Bergman H, Monette J, Noiseux N, Perrault $L P$, Alexander KP, Langlois Y, Dendukuri N, Chamoun P, Kasparian G, Robichaud S, Gharacholou SM, Boivin JF. Gait speed as an incremental predictor of mortality and major morbidity in elderly patients undergoing cardiac surgery. J Am Coll Cardiol. 2010;56:1668-76.

12. Schoenenberger AW, Moser A, Bertschi D, Wenaweser P, Windecker S, Carrel T, Stuck AE, Stortecky S. Improvement of risk prediction after Transcatheter aortic valve replacement by combining frailty with conventional risk scores. JACC Cardiovasc Interv. 2018;11:395-403.

13. Ungar A, Mannarino G, van der Velde N, Baan J, Thibodeau MP, Masson JB, Santoro G, van Mourik M, Jansen S, Deutsch C, Bramlage P, Kurucova J, Thoenes M, Maggi S, Schoenenberger AW. Comprehensive geriatric assessment in patients undergoing transcatheter aortic valve implantation results from the CGA-TAVI multicentre registry. BMC Cardiovasc Disord. 2018;18(1):1. https://doi.org/10.1186/s12872-017-0740-x.

14. Rubenstein LZ, Stuck AE. Multidimensional geriatric assessment. In: Sinclair AJ, Morley JE, Vellas B, editors. Principles and Practice of Geriatric Medicine. 5th ed: Wiley; 2012. p. 1377-86. https://onlinelibrary.wiley.com/doi/book/1 0.1002/9781119952930\#.Xy_2KwzBAkE.email.

15. Rockwood K, Dobbs AR, Rule BG, Howlett SE, Black WR. The impact of pacemaker implantation on cognitive functioning in elderly patients. J Am Geriatr Soc. 1992:40:142-6.

16. Brignole $M$, Auricchio A, Baron-Esquivias $G$, Bordachar $P$, Boriani $G$, Breithardt OA, Cleland J, Deharo JC, Delgado V, Elliott PM, Gorenek B, Israel CW, Leclerca C, Linde C, Mont L, Padeletti L, Sutton R, Vardas PE, ESC Committee for Practice Guidelines (CPG), Zamorano $J \mathrm{~L}$, Achenbach $\mathrm{S}$, Baumgartner H, Bax JJ, Bueno H, Dean V, Deaton C, Erol C, Fagard R, Ferrari R, Hasdai D, Hoes AW, Kirchhof P, Knuuti J, Kolh P, Lancellotti P, Linhart A, Nihoyannopoulos P, Piepoli MF, Ponikowski P, Sirnes PA, Tamargo JL, Tendera M, Torbicki A, Wijns W, Windecker S, Document Reviewers, Kirchhof P, Blomstrom-Lundqvist C, Badano LP, Aliyev F, Bänsch D, Baumgartner H, Bsata W, Buser P, Charron P, Daubert JC, Dobreanu D, Faerestrand S, Hasdai D, Hoes AW, Heuzey JY, Mavrakis H, McDonagh T, Merino JL, Nawar MM, Nielsen JC, Pieske B, Poposka L, Ruschitzka F, Tendera M, Van Gelder IC, Wilson CM. 2013 ESC Guidelines on cardiac pacing and cardiac resynchronization therapy: the task force on cardiac pacing and resynchronization therapy of the European Society of Cardiology (ESC). Developed in collaboration with the European heart rhythm association (EHRA). Eur Heart J. 2013;34:2281-329.

17. Charlson ME, Pompei P, Ales KL, Mackenzie CR. A new method of classifying prognostic comorbidity in longitudinal studies: development and validation. J Chronic Dis. 1987;40:373-83.

18. Folstein MF, Folstein SE, McHugh PR. "Mini-mental state". A practical method for grading the cognitive state of patients for the clinician. J Psychiatr Res. 1975;12:189-98.

19. Podsiadlo D, Richardson S. The timed "up \& go": a test of basic functional mobility for frail elderly persons. J Am Geriatr Soc. 1991;39:142-8. 
20. Guigoz Y, Lauque S, Vellas BJ. Identifying the elderly at risk for malnutrition. The mini nutritional assessment. Clin Geriatr Med. 2002;18:737-57.

21. Katz S, Ford AB, Moskowitz RW, Jackson BA, Jaffe MW. Studies of illness in the aged. The index of ADL: a standardized measure of biological and psychosocial function. JAMA. 1963;185:914-9.

22. Lawton MP, Brody EM. Assessment of older people: self-maintaining and instrumental activities of daily living. Gerontologist. 1969;9:179-86.

23. Hoyl MT, Alessi CA, Harker JO, Josephson KR, Pietruszka FM, Koelfgen M, Mervis JR, Fitten LJ, Rubenstein LZ. Development and testing of a five-item version of the geriatric depression scale. J Am Geriatr Soc. 1999;47:873-8.

24. Krzemień-Wolska K, Tomasik A, Wojciechowska C, Barańska-Pawełczak K, Nowalany-Kozielska E, Jacheć W. Prognostic factors in patients with an implanted pacemaker after 80 years of age in a 4-year follow-up. Gerontology. 2018;64:107-17.

25. Steinbach M, Douchet MP, Bakouboula B, Bronner F, Chauvin M. Outcome of patients aged over 75 years who received a pacemaker to treat sinus node dysfunction. Arch Cardiovasc Dis. 2011;104:89-96.

26. Puts MT, Hsu T, Mariano C, Monette J, Brennenstuhl S, Pitters E, Ray J, WanChow-Wah D, Kozlowski N, Krzyzanowska M, Amir E, Elser C, Jang R, Prica A, Krahn M, Beland F, Bergman S, Koneru R, Lemonde M, Szumacher E, Zidulka J, Fung S, Li A, Emmenegger U, Mehta R, Flemming K, Breunis H, Alibhai SM. Clinical and Cost-effectiveness of a Comprehensive geriatric assessment and management for Canadian elders with Cancer-the 5C study: a study protocol for a randomised controlled phase III trial. BMJ Open. 2019;9(5): e024485.

27. Bachmann S, Finger C, Huss A, Egger M, Stuck AE, Clough-Gorr KM. Inpatient rehabilitation specifically designed for geriatric patients: systematic review and meta-analysis of randomised controlled trials. BMJ. 2010;340: C1718.

28. Ellis G, Whitehead MA, Robinson D, O'Neill D, Langhorne P. Comprehensive geriatric assessment for older adults admitted to hospital: meta-analysis of randomised controlled trials. BMJ. 2011;343:d6553.

\section{Publisher's Note}

Springer Nature remains neutral with regard to jurisdictional claims in published maps and institutional affiliations.

Ready to submit your research? Choose BMC and benefit from:

- fast, convenient online submission

- thorough peer review by experienced researchers in your field

- rapid publication on acceptance

- support for research data, including large and complex data types

- gold Open Access which fosters wider collaboration and increased citations

- maximum visibility for your research: over $100 \mathrm{M}$ website views per year

At $\mathrm{BMC}$, research is always in progress.

Learn more biomedcentral.com/submissions 